

\title{
Photochemistry of Biologically Important Transition Metal Complexes. I. Cyanocobalamin and Related Corrin Complexes of Rhodium(III)
}

\author{
A. Vogler, R. Hirschmann, H. Otto, and H. Kunkely
}

Institut für Chemie, Universität Regensburg, 8400 Regensburg, Germany

\section{Absorptionsspektren, sichtbar und ultraviolett / Emissionsspektren / Komplexverbindungen / Photochemie}

The quantum yield of the well known photoaquation of cyanocobalamin (vitamin $\left.\mathbf{B}_{12}\right)$ was determined $\left(\phi \sim 10^{-4}\right)$ and was found to be independent of the irradiating wavelength. In addition cyanocobalamin did not show the characteristic corrin phosphorescence. In agreement with an earlier suggestion it is concluded that the excitation energy initially absorbed by the corrin ligand is rapidly transferred to a reactive excited LF state which lies below the lowest corrin triplet. This conclusion is supported by the behavior of corrin complexes of $\mathrm{Rh}(\mathrm{III})$. Contrary to cyanocobalamin the complex dicyanorhodium(III)-corrin did not undergo a photoaquation but has been shown to emit a strong corrin phosphorescence. These observations are consistent with the assumption that the lowest excited LF state lies now well above the lowest corrin triplet. If both axial cyanide ligands which have a strong field are replaced by the weak-field ligand chloride the energy of the lowest excited LF state should drop considerably. The behavior of dichlororhodium(III)-corrin indicates that the lowest corrin triplet lies only slightly below the lowest excited LF state which is responsible for the photoreactivity. The reactive LF state may be populated from the lowest corrin triplet by thermal activation. At $77 \mathrm{~K}$ dichlororhodium(III)-corrin showed a strong corrin phosphorescence. At room temperature this emission was essentially quenched and the complex underwent a photoaquation.

Die Quantenausbeute der Photoaquotisierung von Cyanocobalamin (Vitamin $\left.\mathbf{B}_{12}\right)$ wurde bestimmt $\left(\phi \sim 10^{-4}\right)$. Die Quantenausbeute war unabhängig von der Wellenlänge des Anregungslichtes. Außerdem zeigte Cyanocobalamin nicht die charakteristische Corrinphosphoreszenz. In Übereinstimmung mit einem früheren Vorschlag wird aus diesen Ergebnissen geschlossen, daß die Anregungsenergie, die zunächst vom Corrinliganden absorbiert wird, rasch auf einen reaktiven angeregten LF-Zustand übertragen wird, der unter dem niedrigsten Corrintriplet liegt. Diese Schlußfolgerung wird durch das Verhalten von Corrinkomplexen von $\mathbf{R h}(\mathrm{III})$ unterstützt. Im Gegensatz zu Cyanocobalamin unterlag Dicyanorhodium(III)-corrin keiner Photoaquotisierung, aber emittiert, wie schon früher gezeigt wurde, eine starke 
Corrinphosphoreszenz. Diese Beobachtungen stimmen mit der Annahme überein, daß der niedrigste angeregte LF-Zustand bei deutlich höheren Energien liegt als das niedrigste Corrintriplet. Wenn beide axiale Cyanidliganden, die ein starkes Ligandenfeld besitzen, durch Chlorid, das ein schwaches Feld hat, ersetzt werden, dann sollte die Energie des niedrigsten angeregten LF-Zustandes beträchtlich absinken. Das Verhalten von Dichlororhodium(III)-corrin weist darauf hin, daß das niedrigste Corrintriplet nur noch geringfügig unter dem niedrigsten angeregten LF-Zustand liegt, der für die Photoreaktivität verantwortlich ist. Der reaktive LF-Zustand kann offensichtlich vom niedrigsten Corrintriplet durch thermische Aktivierung besetzt werden. Bei $77 \mathrm{~K}$ zeigte Dichlororhodium(III)-corrin eine starke Corrin-

phosphoreszenz. Bei Raumtemperatur war diese Emission praktisch gelöscht, und der Komplex unterlag einer Photoaquotisierung.

\section{Introduction}

The photochemistry is certainly an important aspect of the chemistry of vitamin $B_{12}$ [1]. Many cobalt(III) corrins undergo light-induced reactions which lead to the breaking of the bond between cobalt and an axial ligand. Heterolytic breaking leads to a substitution. Homolytic bond splitting, which is simply a redox reaction; produces $\mathrm{B}_{12 \mathrm{r}}$ containing $\mathrm{Co}(\mathrm{II})$, and an oxidized ligand radical which may undergo further reactions.

These photoreactions are typical for transition metal complexes $[2,3]$ and particularly similar to those of cyano complexes of $\mathrm{Co}(\mathrm{III})$. Cyanocobalamin and ammoniacobalamin undergo a photoaquation of cyanide [4-6] and ammonia $[6,7]$. This behavior corresponds to that of $\mathrm{Co}(\mathrm{CN})_{6}^{3-}$ and $\mathrm{Co}(\mathrm{CN})_{5} \mathrm{NH}_{3}^{2-}$ which show also a photoaquation of $\mathrm{CN}^{-}$ [8-10] and $\mathrm{NH}_{3}$ [11]. If the sixth ligand is an carbanion as in the coenzyme or methylcobalamin a photoredox reaction takes place with the formation of $\mathrm{B}_{12 \mathrm{r}}$ [1]. This reaction finds its counterpart in the photolysis of $\left[\mathrm{Co}(\mathrm{CN})_{5} \mathrm{CH}_{2}-\mathrm{C}_{6} \mathrm{H}_{5}\right]^{3-}$ which yields $\mathrm{Co}(\mathrm{CN})_{5}^{3-}$ and a benzyl radical [13]. Since the electronic structure of the cyano complexes is relatively simple it has been possible to show that their photosubstitutions are initiated by excited LF states while a CT state is responsible for the photoredox behavior.

However, in the case of corrin complexes of $\mathrm{Co}$ (III) such a relationship is not apparent. The electronic spectra of $\mathbf{B}_{12}$ compounds are determined by the very intense absorptions of the corrin ligand [1]. Any other bands as CT absorptions and particularly LF bands which are of low intensity have not been identified and may be hidden under or obscured by the intense bands which have been assigned to spin-allowed $\pi \pi^{*}$ transitions of the corrin ligand. Since the photoreactions occur upon light absorption of the corrin ligand one could assume that excited states of corrin are responsible for the photoreactivity. But there is no obvious explanation how an excited state of the corrin may initiate reactions in which the metal center and an axial ligand are involved while the corrin ligand does not participate in these reactions.

Only recently Gardiner and Thomson investigated the luminescence properties of metallocorrins [15]. While neither cyanocobalamin [16] nor a synthetic dicyanocobalt(III)corrin [15] do show the characteristic phosphorescence of the corrin ligand, the complex dicyanorhodium(III)-corrin exhibits a strong corrin phosphorescence [15]. These results led to the conclusion that in the case of the cobalt complex excited LF states lying below the lowest triplet of the corrin ligand quench the emission of the latter by facilitating rapid radiationsless transitions to excited LF states. If $\mathrm{Co}$ (III) is replaced by the homologous $\mathrm{Rh}(\mathrm{III})$ the lowest excited LF state is shifted to higher energy and lies now above the lowest corrin triplet. As a consequence the $\mathrm{Rh}(\mathrm{III})$ complex shows the corrin phosphorescence. This interpretation implies that the photo- substitution of corrin complexes of $\mathrm{Co}$ (III) is initiated by excited LF states. On the other hand, one may expect that corrin complexes of $\mathrm{Rh}$ (III) do not undergo light-induced substitution reactions. Therefore the present study was undertaken to compare the photochemical and the photophysical behavior of cobalt(III) and rhodium(III) corrins.

\section{Experimental}

Materials. Cyanocobalamin was purchased from E. Merck, Darmstadt. It was used without further purification. A sample of dichlororhodium(III)-1;2,2,7,7,12,12-heptamethyl-15-cyanocorrin *) (17 mg) was supplied by Prof. A. Eschenmoser of the ETH Zürich. A part of this sample ( $\sim 8 \mathrm{mg}$ ) was converted to dicyanorhodium(III)1,2,2,7,7,12,12-heptamethyl-15-cyanocorrin by the method of H.-U. Blaser [17].

Photolysis Procedure. The light source used was a $450 \mathrm{~W}$ Osram high-pressure xenon lamp XBO 450. A Schott WG 320 filter was used for irradiation with light of wavelengths longer than $300 \mathrm{~nm}$. A Schott interference filter PIL 313 was used for irradiation at $313 \mathrm{~nm}$. The filter combination Schott WG 360 and Schott UG 11 transmitted light between 340 and $380 \mathrm{~nm}$ with a maximum of transmittance at $350 \mathrm{~nm}$. A Balzers interference filter $\mathrm{K} 4$ was used for the irradiation at $560 \mathrm{~nm}$ (half width $50 \mathrm{~nm}$ ).

The photolysis were carried out in spectrophotometer cells. Cyanocobalamin was photolyzed in aqueous solutions at natural $p \mathrm{H}(\sim 6)$. Aqueous solutions of the $\mathrm{Rh}(\mathrm{III})$ complexes were prepared by dissolving them in a small amount of methanol and diluting with a large excess of water. In some experiments the solutions were degassed by several freeze-thaw cycles on a vacuum line. For quantum-yield measurements the complex concentrations were such as to have essentially complete light absorption. The total amount of photolysis was limited to less than $5 \%$ to avoid light absorption by the photoproduct. Absorbed light intensities were determined by Ferrioxalate [18] and Reineckate [19] actinometry.

Measurements. Visible and ultraviolet spectra were measured with a Cary 14 recording spectrophotometer and a Zeiss PMQ II spectrophotometer for measurements at selected wavelengths. Emission spectra were recorded on a modified apparatus described elsewhere [20]. This apparatus was equipped with a cooled RCA C 7164 R photomultiplier. Samples were in the solid state or dissolved in methanol-water mixtures.

\section{Results}

Cyanocobalamin. The absorption spectrum of aqueous cyanocobalamin (Fig. 1) agrees wellwwith those reported in the literature [1] The maxima of the characteristic $\alpha, \beta$ und $\gamma$ bands appear at $548 \mathrm{~nm}$ $\left(\varepsilon=0.84 \cdot 10^{4}\right), 516 \mathrm{~nm}\left(\varepsilon=0.74 \cdot 10^{4}\right)$, and $361 \mathrm{~nm}\left(\varepsilon=2.75 \cdot 10^{4}\right)$. Upon irradiation with light of wavelengths longer than $300 \mathrm{~nm}$ cyanocobalamin underwent the well known photoaquation as indicated by the accompanying spectral changes which include clear isosbestic points (Fig. 1). Prolonged irradiation led to the spectrum of aquocobalamin [21] which exhibits the maximum of the $\gamma$ band at $350 \mathrm{~nm}\left(\varepsilon=2.60 \cdot 10^{4}\right)$. If light absorption by cyanocobalamin was complete the reaction followed a zeroth order kinetics. The change of the extinction at $361 \mathrm{~nm}$ was used to fol-

*) The abbreviation corrin is used in this paper to designate the 1,2,2,7,7,12,12-heptamethyl-15-cyanocorrin ligand of the $\mathrm{Rh}(\mathrm{III})$ complexes. 
low the disappearance of cyanocobalamin. Quantum yields were determined at two irradiating wavelengths corresponding to the $\alpha$ and $\beta$ band $\left(\lambda_{\text {irr }}=560 \mathrm{~nm}\right)$ and the $\gamma$ band $\left(\lambda_{\text {irr }}=350 \mathrm{~nm}\right)$. The quantum yields were $\phi=4 \cdot 10^{-4}$ and $\phi=3 \cdot 10^{-4}$. Since the precision at such low yields is not very high the quantum yields are considered to be the same within the experimental error. Degassing of the solution did not affect these measurements. No emission of solid cyanocobalamin was detected at different exciting wavelengths including the $\alpha$ and $\gamma$ bands at temperatures down to about $4 \mathrm{~K}$. Since the sensitivity of the detector is limited to wavelengths up to about $950 \mathrm{~nm}$ it is not excluded that cyanocobalamin shows any emission at longer wavelengths.

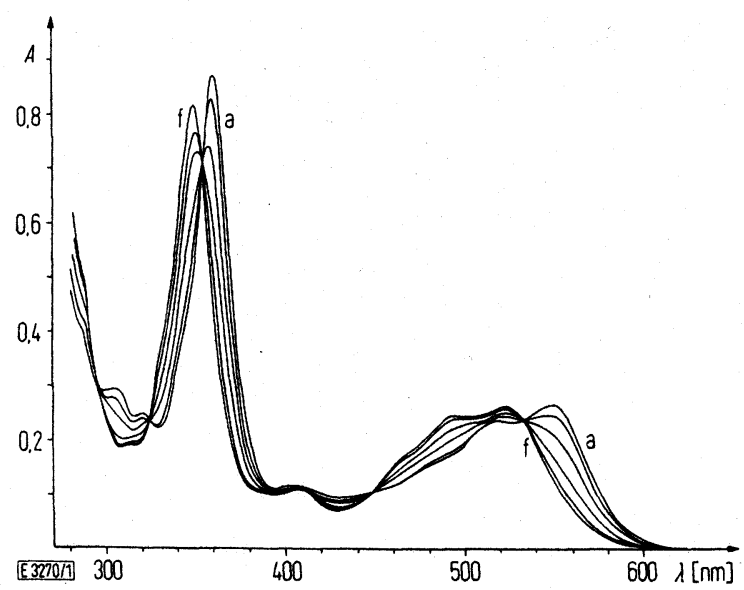

Fig. 1

Spectral changes during the photolysis of $3,16 \cdot 10^{-5} \mathrm{M}$ cyanocobalamin, irradiating wavelengths $>300 \mathrm{~nm}$. a: $0 \mathrm{~min}, \mathrm{~b}: 1 \mathrm{~min}$, C: $4 \mathrm{~min}, \mathrm{~d}: 10 \mathrm{~min}$, e: $20 \mathrm{~min}$, f: $50 \mathrm{~min}$ irradiation time

Dicyanorhodium(III)-corrin. The absorption spectrum of $(\mathrm{CN})_{2} \mathrm{Rh}(\mathrm{III})$-corrin (Fig. 2) agrees well with that measured by Blaser [17] ( $\alpha$-band: $\lambda_{\max }=517 \mathrm{~nm}, \varepsilon=1.29 \cdot 10^{4}, \beta$-band: $\lambda_{\max }=$ $489 \mathrm{~nm}, \varepsilon=1.52 \cdot 10^{4}, \gamma$-band: $\left.\lambda_{\max }=331 \mathrm{~nm}, \varepsilon=2.83 \cdot 10^{4}\right)$. Upon irradiation with light of wavelengths longer than $300 \mathrm{~nm}$ corresponding to the $\alpha, \beta$, and $\gamma$ bands the spectrum of a degassed solution did not change. (CN) ${ }_{2} \mathrm{Rh}$ (III)-corrin did apparently not undergo any photochemical reaction. If oxygen was not excluded the irradiation led to a slow decomposition of the complex as indicated by the decrease of the extinction at all wavelengths longer than $300 \mathrm{~nm}$.

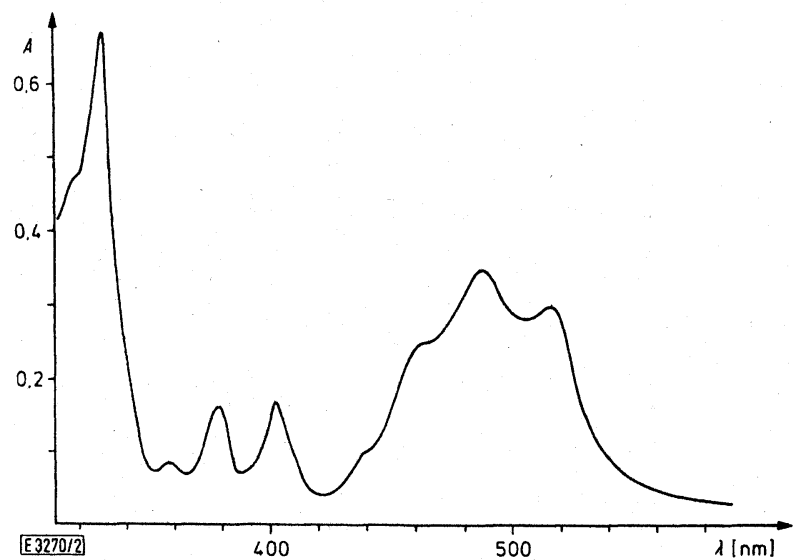

Fig. 2

Absorption spectrum of $2.37 \cdot 10^{-5} \mathrm{M}(\mathrm{CN}){ }_{2} \mathrm{Rh}(\mathrm{III})$-corrin

Dichlororhodium (III)-corrin. The absorption spectrum of aqueous $\mathrm{Cl}_{2} \mathrm{Rh}$ (III)-corrin (Fig. 3) exhibits the $\alpha, \beta$ and $\gamma$ bands at $499 \mathrm{~nm}$ $\left(\varepsilon=1.25 \cdot 10^{4}\right), 476 \mathrm{~nm}\left(\varepsilon=1.68 \cdot 10^{4}\right)$, and $324 \mathrm{~nm}\left(\varepsilon=2.28 \cdot 10^{4}\right)$
[17]. Upon irradiation of these bands with light of wavelengths longer than $300 \mathrm{~nm}$ a photoreaction took place which was accompanied by spectral changes (Fig. 3) including clear isosbestic points. Since the characteristic absorption maxima were shifted to slightly other wavelengths it is concluded that only at the axial ligand positions a change took place. In analogy to the photochemical reactions of Co(III)-corrins it is assumed that a chloride ligand was substituted by water with the formation of $\left(\mathrm{H}_{2} \mathrm{O}\right)(\mathrm{Cl}) \mathrm{Rh}(\mathrm{III})$ corrin. Although a simultaneous substitution of both axial $\mathrm{Cl}^{-}$ ligands can not be excluded, such a reaction is not likely to occur. After prolonged irradiation the photolysis went to completion.

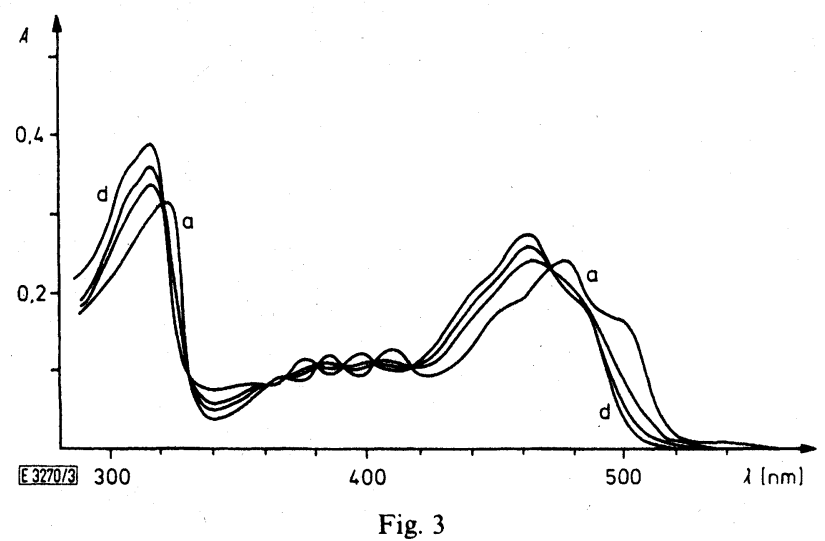

Spectral changes during the photolysis of $1.71 \cdot 10^{-5} \mathrm{M} \mathrm{Cl}_{2} \mathrm{Rh}(\mathrm{III})$ corrin, irradiating wavelengths $>300 \mathrm{~nm}$ a $: 0 \mathrm{~min}, \mathrm{~b}: 5 \mathrm{~min}, \mathrm{c}: 10 \mathrm{~min}$, $\mathrm{d}: 20$ min irradiation time

Further spectral variations did not occur. This photoreaction was hardly affected by deaeration. In the presence of oxygen a very slow decomposition took place only after a very long irradiation time.

Since the spectra of $\mathrm{Cl}_{2} \mathrm{Rh}(\mathrm{III})$-corrin and $\left(\mathrm{H}_{2} \mathrm{O}\right)(\mathrm{Cl}) \mathrm{Rh}(\mathrm{III})$ corrin are known the photoaquation can be studied quantitatively. However, the sample of the dichloro complex, which was left after the qualitative measurements were done, was too small to determine precise quantum yields. Upon irradiation of the $\dot{\gamma}$-band $\left(\lambda_{\text {irr }}=\right.$ $313 \mathrm{~nm}$ ) the quantum yield of the photoaquation was roughly estimated to be $10^{-2}$

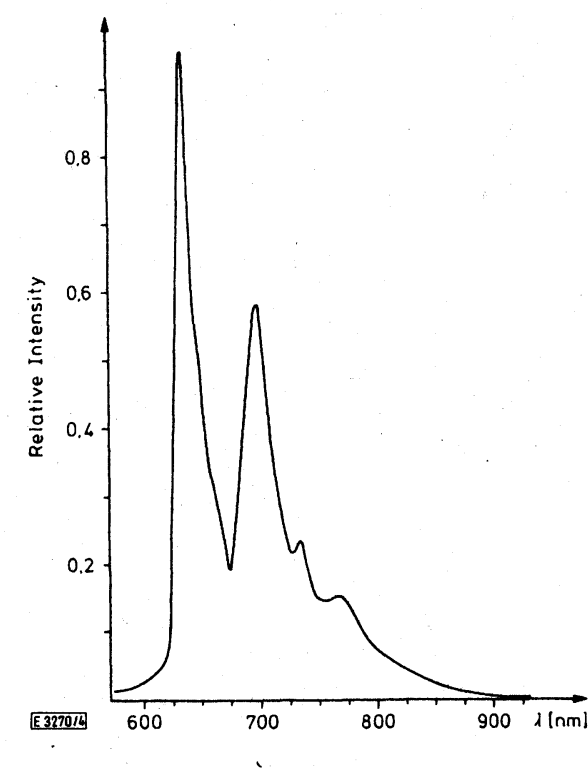

Fig. 4

Emission spectrum of solid $\mathrm{Cl}_{2} \mathrm{Rh}(\mathrm{III})$-corrin, excitation wavelength $436 \mathrm{~nm}$, temperature: $77 \mathrm{~K}$ (relative intensity not corrected for multiplier response) 
At $77 \mathrm{~K}$ excitation at two different wavelengths ( 366 and $436 \mathrm{~nm}$ ) led to an intense red luminescence of $(\mathrm{Cl})_{2} \mathrm{Rh}$ (III)-corrin which was either in the solid state (Fig. 4) or in a solution of methanol and water $(1: 1)$, frozen to a rigid glass. The concentration of the complex was smaller than $10^{-4} \mathrm{M}$. At this concentration an association of the complex molecules should not be important. The observed luminescence is apparently the phosphorescence of the corrin ligand in agreement with the results of Gardiner and Thomson [15]. The solid material showed this phosphorescence at room temperature too, but the emission was very weak. However, we were not able to detect this phosphorescence in degassed solution at room temperature.

\section{Discussion}

The absorption spectra of metal complexes containing the corrin ligand show very intense absorption bands, particularly the so-called $\alpha, \beta$, and $\gamma$ bands, which have been assigned to spin-allowed $\pi \pi^{*}$ transitions of the corrin ligand [1]. Although the wavelengths and intensities of the absorption maxima depend on the coordination center and on additional ligands to some extent, the pattern of the spectra is not affected by these influences. Hence it is certainly reasonable to assign these absorptions to intraligand transitions of the corrin ligand. These characteristic bands appear also in the spectra of cyanocobalamin, $(\mathrm{CN})_{2} \mathrm{Rh}(\mathrm{III})$-corrin, and $\mathrm{Cl}_{2} \mathrm{Rh}(\mathrm{III})$ corrin. Since any other bands were not detected they must either occur at higher energies or they are hidden under or obscured by the intense absorptions of the corrin ligand. These other bands belong to CT and LF excited states which involve the coordination center.

Since cyanocobalamin and the $\mathrm{Rh}(\mathrm{III})$ corrins are pseudooctahedral complexes having a low-spin $\mathrm{d}^{6}$ ground state their electronic structures may be compared with those of other $\mathrm{Co}(\mathrm{III})$ and $\mathrm{Rh}(\mathrm{III})$ complexes [22]. $\mathrm{Rh}(\mathrm{III})$ is very resistant toward oxidation and reduction. Consequently, CT states are expected and were observed only at very high energies. On the other hand, $\mathrm{Co}(\mathrm{III})$ may be reduced to $\mathrm{Co}(\mathrm{II})$. Hence CT (ligand to metal) transitions occur at moderate energies depending on the reducing power of the ligands. Generally these CT bands are quite intense and easily identified. The excited LF states of these $d^{6}$ complexes are singlets and triplets. The lowest one is a triplet. The spin-forbidden LF bands are of very low intensity and difficult to detect. The spin-allowed LF bands, although not very intense too, are not difficult to identify since they appear generally at longer wavelengths than the CT bands. The excited LF states of $\mathrm{Rh}$ (III) complexes are of much higher energy than those of the corresponding $\mathrm{Co}(\mathrm{III})$ complexes.

According to these considerations the lowest excited LF states of cyanocobalamin occur certainly at lower energies than those of the Rh(III) corrins. But in both cases it is expected that the lowest CT states lie above the lowest LF states. However, the relative ordering of the lowest excited corrin and LF states is much more difficult to assess since the LF absorptions have not been observed and should be hidden under the intense corrin bands. If the LF absorptions do occur at shorter wavelengths than the corrin bands it is nevertheless not allowed to conclude that the lowest excited state of the corrin ligand lies below the lowest excited LF state because LF excitation of $\mathrm{d}^{6}$-complexes leads to very large geometrical changes indicated by huge Stoke's shifts of absorption and emission [23, 24].

Emission spectroscopy provides a tool to determine the nature of the lowest excited state. The investigation of the luminescence of a large number of transition metal complexes [23-25], particularly low-spin $d^{6}$ complexes, has led to the general rule that "in the absence of photochemistry from upper excited states, emission from a transition metal complex with an unfilled $\mathrm{d}$ shell will occur from the lowest electronic excited state in the molecule or from those states that can achieve a significant Boltzmann population relative to the lowest excited state" [26]. A similar rule has been derived from extensive investigations of porphyrin complexes [27] which are related to corrin complexes. According to this rule the characteristic phosphorescence from the lowest triplet of porphyrin (or corrin in our case) occurs only if this triplet is the lowest excited state of the complex. Since dicyanocobalt(III)corrin does not show the corrin phosphorescence Gardiner and Thomson have suggested that excited LF states lie below the lowest corrin triplet and are reponsible for the photoreactivity [15]. The results of the present study support this assumption. Cyanocobalamin did not emit the corrin phosphorescence irrespective of the excitation energy and at temperatures down to $4 \mathrm{~K}$. In addition the quantum yield of photoaquation did not depend on the irradiating wavelengths. It is suggested that an efficient population of lower LF states is facilitated by rapid radiationless transitions from the corrin singlets initially excited. The lowest LF state is a triplet. This triplet is probably the reactive state of $d^{6}$-complexes as it has been suggested in the case of $\mathrm{Co}(\mathrm{CN})_{6}^{3-}[28]$. The low quantum yield of photoaquation of cyanocobalamin means then that either the deactivation of the excited corrin singlets leads to the lowest excited LF singlet which does not undergo efficient intersystem crossing to the reactive LF triplet or, more likely, the population of the reactive triplet is very effective, however, its deactivation does not only occur by the photoreaction but also by an efficient radiationless transition to the ground state. These explanations have been advanced to explain the low quantum yields of photoaquation which have been obtained upon LF excitation of $\mathrm{Co}$ (III) ammines $[28,29]$.

Since the LF states of Rh(III) complexes have much higher energies than those of the corresponding $\mathrm{Co}$ (III) complexes it is not surprising that the lowest LF state of $(\mathrm{CN})_{2} \mathrm{Rh}(\mathrm{III})$ corrin lies well above the lowest corrin triplet. This has been shown by Gardiner and Thomson who observed the corrin phosphorescence at $77 \mathrm{~K}$ as well as at room temperature [15]. This behavior is also consistent with our result that $(\mathrm{CN})_{2} \mathrm{Rh}(\mathrm{III})$-corrin does not undergo a photoaquation although LF excitation of Rh(III) complexes generally leads to higher quantum yields of photoaquation than that of $\mathrm{Co}$ (III) complexes [30]. According to the rule mentioned above [26] the reactive LF state of $(\mathrm{CN})_{2} \mathrm{Rh}(\mathrm{III})$-corrin may be populated but its radiationless deactivation to the emitting corrin triplet is much faster than the photoaquation. Alternatively, the reactive $\mathrm{LF}$ state may not be populated at all because its energy is too high. Our observation that $(\mathrm{CN})_{2} \mathrm{Rh}(\mathrm{III})$-corrin underwent a photodecomposition in the presence of oxygen is in agreement with earlier results of 
Eschenmoser [31] who could show that this decomposition seems to be a photosensitized oxidation by singlet oxygen which may be formed by energy transfer from the corrin ligand. The quenching of the corrin phosphorescence of $(\mathrm{CN})_{2} \mathrm{Rh}(\mathrm{III})$-corrin by oxygen should have the same origin.

The behavior of $\mathrm{Cl}_{2} \mathrm{Rh}(\mathrm{III})$-corrin is very interesting since it represents an intermediate case between cyanocobalamin and $(\mathrm{CN})_{2} \mathrm{Rh}$ (III)-corrin. The relative ordering of different excited states and also energy differences between them can not only be varied by an exchange of the metal but also by an appropriate choice of the ligands [23]. If both axial cyanide ligands which are strong-field ligands are replaced by the weak-field ligand chloride the lowest excited LF state is expected to drop considerably in energy. Our results suggest that the lowest $\mathrm{LF}$ state of $\mathrm{Cl}_{2} \mathrm{Rh}$ (III)-corrin lies only slightly above the lowest corrin triplet. The former can now be populated from the corrin triplet by thermal activation. Consequently, a strong corrin phosphorescence was observed at low temperatures while at room temperature this emission was essentially quenched and the complex underwent a photoaquation. This mechanism is also consistent with the observation that the photosensitized oxidation of $\mathrm{Cl}_{2} \mathrm{Rh}$ (III)corrin by singlet oxygen is much less efficient compared to that of $(\mathrm{CN})_{2} \mathrm{Rh}$ (III)-corrin.

We acknowledge gratefully Prof. A. Eschenmoser who has generously supplied a sample of dichlororhodium(III)-corrin. We thank the Deutsche Forschungsgemeinschaft and the Fonds der Chemischen Industrie for support of this research.

\section{References}

[1] For a review see J. M. Pratt, Inorganic Chemistry of Vitamin $B_{12}$, Academic Press, New York 1972.

[2] A. W. Adamson and P. D. Fleischauer (Eds.), Concepts of Inorganic Photochemistry, Wiley-Interscience, New York 1975.

[3] V. Balzani and V. Carassiti, Photochemistry of Coordination Compounds, Academic Press, New York 1970.

[4] W. L. Veer, J. H. Edelhausen, H. G. Wijenga, and J. Lens, Biochim. biophysica Acta 6, 225 (1950).

[5] G. E. Boxer and J. C. Rickards, Arch. Biochemistry 30, 382 (1951).

[6] J. M. Pratt, J. chem. Soc. 1964, 515.

[7] G. Cooley, B. Ellis, V. Petrow, G. H. Beaven, E. R. Holiday, and E. A. Johnson, J. Pharmacy Pharmacol. 3, 271 (1951).
[8] A. W. Adamson and A. H. Sporer, J. Amer. chem. Soc. 80, 3865 (1958); J. inorg. nucl. Chem. 8, 209 (1958).

[9] L. Moggi, F. Boletta, V. Balzani, and F. Scandola, J. inorg. nucl. Chem. 28, 2589 (1966).

[10] A. W. Adamson, A. Chiang, and E. Zinato, J. Amer. chem. Soc. 91,5467 (1969).

[11] R. Sriram, Ph. D. Dissertation, University of Southern California, 1972; see also ref. [12].

[12] E. Zinato, Concepts of Inorganic Photochemistry (A. W. Adamson and P. D. Fleischauer, Eds.), chapter 4, WileyInterscience, New York 1975.

[13] A. Vogler and R. Hirschmann, unpublished results; see also ref. [14].

[14] J. F. Endicott, Concepts of Inorganic Photochemistry (A. W. Adamson and P. D. Fleischauer, Eds.), chapter 3, WileyInterscience, New York 1975.

[15] M. Gardiner and A. J. Thomson, J. chem. Soc., Dalton, 820 (1974).

[16] A. J. Thomson, J. Amer. chem. Soc. 91, 2780 (1969).

[17] H.-U. Blaser, Dissertation, ETH Zürich, Nr. 4662 (1971).

[18] C. G. Hatchard and C. A. Parker, Proc. Roy. Soc. [London], Ser. A, 235, 518 (1956).

[19] E. E. Wegner and A. W. Adamson, J. Amer. chem. Soc. 88, 394 (1966).

[20] H. Yersin and G. Gliemann, Meßtechnik 80, 99 (1972).

[21] J. M. Pratt and R. G. Thorp, J. chem. Soc. (A), 1966, 187.

[22] For a review and recent references on the electronic spectra of $\mathrm{Co}$ (III) and $\mathrm{Rh}$ (III) complexes see ref. [2].

[23] G. A. Crosby, Acc. Chem. Res. 8, 231 (1975).

[24] a) L. S. Forster (chapter 1), b) G. B. Porter (chapter 2), Concepts of Inorganic Photochemistry (A. W. Adamson and P. D. Fleischauer, Eds.), Wiley-Interscience, New York 1975.

[25] P. D. Fleischauer and P. Fleischauer, Chem. Reviews 70, 199 (1970).

[26] J. N. Demas and G. A. Crosby, J. Amer. chem. Soc. 92, 7262 (1970).

[27] D. L. Eastwood and M. Gouterman, J. Molec. Spectroscopy 35,359 (1970).

[28] For a discussion see ref. [12].

[29] R. A. Pribush, C. K. Poon, C. M. Bruce, and A. W. Adamson, J. Amer. chem. Soc. 96, 3027 (1974).

[30] P. C. Ford, R. E. Hintze, and J. D. Petersen, Concepts of Inorganic Photochemistry (A. W. Adamson and P. D. Fleischauer, Eds.), chapter 5, Wiley-Interscience, New York 1975

[31] A. Eschenmoser, private communication; see also A. Eschenmoser, XXIIIrd Int. Congr. Pure Appl. Chem., Boston, Suppl. Pure Appl. Chem. 2, 69 (1971).

(Eingegangen am 17. Oktober 1975) E 3270 